\title{
Actor-Partner Effects of Mother-Adolescent Communication and Conflict on Psychological Well- Being for Mothers and Male/Female Adolescents
}

\author{
Yeon Soo Cho ${ }^{1}$, Sae-Young $\mathrm{Han}^{2}$ \\ Ph. D., Department of Child Development, Ewha Womans University, Seoul, Korea ${ }^{1}$ \\ Professor, Department of Child Development, Ewha Womans University, Seoul, Korea² \\ 어머니와 남녀 청소년 자녀가 지각한 모-자녀 의사소통 및 \\ 갈등이 심리적 안녕감에 미치는 자기-상대방효과 \\ 조연수 ${ }^{1}$, 한세영 $^{2}$ \\ 이화여자대학교 아동학과 박사 ${ }^{1}$, 이화여자대학교 아동학과 교수 ${ }^{2}$
}

Objectives: Guided by the family systems theory (Bowen, 1966) and the Actor-Partner Interdependence Model (APIM; Cook \& Kenny, 2005), this study examined the actor-partner effects of mother-adolescent communication on the psychological well-being of mothers and their adolescent children via motheradolescent conflict and the differences between female and male adolescents.

Methods: A total of 249 dyads of mothers and their adolescent children (age 13-16) in South Korea completed questionnaires on mother-adolescent communication, mother-adolescent conflict, and psychological well-being, respectively. The data were analyzed using Pearson's correlation, path model analysis, and multiple group analysis.

Results: First, the findings showed both partial actor and partner effects of perceived motheradolescent communication on psychological well-being through a perceived level of conflict in both male and female adolescents and mother pairs. In addition, we examined sex differences for the aforementioned indirect pathways. There were sex differences in the indirect actor effects, in that mothers' and adolescents' own perceived communication had differential effects on psychological wellbeing indirectly through perceived conflict. The indirect partner effects also differed between male and female adolescents. The results of this study are meaningful because they emphasize the bidirectionality of the relationships among these variables.

Conclusion: The findings contribute to the literature by highlighting the dyadic process in which mother-adolescent communication, conflict, and psychological well-being perceived by mothers and adolescents affect themselves as well as each other. This study is meaningful because the results emphasize the relationships between these variables. In utilizing a family systems approach, this study's findings can aid in developing parent education programs, counseling interventions, and family policies that improve individuals' psychological well-being.

Keywords: mother, adolescent, communication, conflict, psychological well-being, actor-partner effects

Corresponding Author: Sae-Young Han, Professor, Department of Child Development, Ewha Womans University, 52, Ewhayeodae-gil, Seodaemungu, Seoul, Korea

E-mail: evenhow@ewha.ac.kr
(c)The Korean Association of Child Studies

This is an Open Access article distributed under the terms of the Creative Commons Attribution Non-Commercial License (http:// creativecommons.org/licenses/by-nc/4.0) which permits unrestricted noncommercial use, distribution, and reproduction in any medium, provided the original work is properly cited. 


\section{Introduction}

청소년기는 안정된 정서를 기반으로 삶의 목적을 정립하고, 자아정체감을 형성하는 시기이기 때문에(Erikson, 1968), 청소 년기에 심리적 안녕감을 가지는 것은 발달적으로 중요하다. 특히 청소년의 심리적 안녕감은 청소년이 과제를 스스로 해결 하고, 개인적 성장을 도모하며, 목표가 있는 삶을 성취하게 하 도록 하는 요인이며(K. Kim, 2006), 삶의 의미에도 영향을 미 치는데 삶의 의미는 자아존중감, 삶의 만족, 행복, 다른 사람 에 대한 태도, 삶에 대한 전반적인 긍정적 태도와 높은 관련성 이 있다(J. W. Chun \& Park, 2006). 또한, 이러한 청소년 자녀 를 둔 어머니의 경우 중년기에 해당하는 것으로 볼 수 있는데, Erikson (1963)은 중년기를 인생의 목표를 성취해가는 인생의 절정기로 보았으며, 노화가 시작되는 자신의 신체적.생리적 변화를 인정하고 적응하며, 사회에 공헌하고 생산성을 획득해 나가면서 중년의 위기에 대처하는 것을 발달 과업으로 보았 다. 이러한 과정에서 청소년 자녀를 둔 어머니들은 이전까지 자녀나 외부로 향했던 관심을 자신의 내부로 옮겨서 자아통합 을 이룩하려는 경향(M.-K. Lee \& Lee, 2015)을 가질 수 있다.

그러나 청소년기는 '질풍노도(strom and stress)'의 시기(Hall, 1969)로 표현되듯이 신체적, 정서적, 사회적으로 급격한 변 화를 경험하고 부정적인 정서가 커지는 시기이며(Han \& Lee, 2005), 중년기는 신체적·생물학적 노화가 시작되면서 젊음의 쇠퇴에서 오는 우울증, 노년의 삶에 대한 준비성 불안 등이 동 시다발적으로 찾아오는 시기이다(H.-G. Lee, 2016). 정리하면, 한 가족체계 내의 청소년 자녀와 어머니는 각각 발달적 변화 와 스트레스를 경험하면서 심리적 안녕감이 위협받을 수 있으 므로, 이들의 심리적 안녕감에 대한 연구가 필요하다.

심리적 안녕감(psychological well-being)이란 개인이 사회구 성원으로서 긍정적인 심리적 기능을 하는 것을 의미한다(Ryff, 1989). Ryff (1989)는 긍정적인 심리적 기능을 정의하기 위하 여 Maslow (1968)의 자아실현, Rogers (1961)의 완전히 기능하 는 사람, Jung (1985/1969)의 개성화, 그리고 Allport (1961)의 성숙에 대한 개념을 포함한 광범위한 문헌을 조사하였으며, 이를 바탕으로 심리적 안녕감을 이루는 6가지 측면의 구성개 념을 자기 수용(self-acceptance), 자율성(autonomy), 긍정적 대 인관계(positive relations with others), 환경통제력(environmental mastery), 삶의 목적(purpose in life), 개인적 성장(personal growth)으로 제시하였다.

이러한 개인의 심리적 안녕감에 있어, 가족관계적 변인은 중요한 요인으로 작용할 수 있다. Bowen (1966)은 가족체계이 론(family system theory)을 통해 가족은 살아있는 유기체와 같 이 하나의 체계로 작동하며, 가족구성원 간의 상호의존성과 의 사소통 등이 이들의 심리적 상태에 영향을 준다는 관점을 제 시하였다. 체계이론의 관점에서 가족구성원 간의 상호작용 과 정은 단순한 원인과 결과(cause-and-effect)가 아닌 상호적 관 계(reciprocal interaction)에 의한 것으로 본다(Becvar \& Becvar, 2013). 가족구성원 중 한 사람의 행동이 누군가의 반응을 불 러일으키고 이는 다시 또 다른 누군가의 다른 반응을 일으키 는 식으로 이들의 행동적 상호작용은 서로에게 복잡하게 얽 혀있기 때문에, 관계 내의 구성원들은 상호적 관계를 유지하 는 자극(stimulus) 이자 피드백(feedback)이 되는 것이다(Bigner, 1989). 이러한 관점에 따르면, 한 가족체계 내에서 어머니와 자 녀 간의 관계는 하나의 하위체계(subsystem)로 볼 수 있으며, 이 들 간의 관계에서 일어나는 상호역동은 어머니와 청소년 자녀 의 심리적 안녕감에 영향을 미칠 것으로 가정해볼 수 있다. 따 라서 본 연구에서는 어머니와 청소년 자녀가 지각한 모-자녀 간 의사소통, 갈등 및 심리적 안녕감 간의 관계를 살펴보았다.

먼저 모-자녀 의사소통은 청소년 자녀와 어머니의 심리적 안녕감에 영향을 미치는 변인으로 보고되어왔다. 청소년들은 생각과 감정을 부모와 문제없이 소통한다고 지각할수록, 즉 부모-자녀 간에 개방적 의사소통을 할수록 행복감(Ahn \& You, 2013; Y.-E. Jang \& Lee, 2015)과 심리사회적 적응이 높은 것으 로 보고되었으며(Y.-M. Lee, Min, \& Lee, 2005), 중학생 자녀를 둔 어머니의 정신건강에 대한 탐색적 연구에서는 자녀와 집안 의 문제에 대해 의사소통을 많이 할수록 어머니가 인지한 우 울, 불안이 낮고, 가족정신건강이 높은 것으로 보고되었다(B. J. Kim, Park, \& Chun, 2005).

나아가, 모-자녀 간의 의사소통은 모-자녀 간의 갈등을 통 해서도 어머니와 청소년 자녀의 심리적 안녕감에 간접적인 영 향을 미칠 수 있을 것으로 가정할 수 있다. 선행연구에 따르 면, 부모와 청소년 모두 미숙한 의사소통 기술로 인해 끊임없 는 가족 간 갈등을 경험하는 것으로 나타났으며(O. N. Kim \& Kim, 1994; E. J. Park \& Kim, 1995), 모-자녀 간에 부정적이고 방어적인 의사소통을 하는, 즉 폐쇄적 의사소통을 사용하는 청소년과 어머니 간의 갈등이 더 큰 것으로 보고되었다(H. S. Jang, 2005).

다음으로, 모-자녀 간의 갈등은 어머니와 청소년 자녀의 심 리적 안녕감에 영향을 미치는 요인으로 작용할 수 있다. 우선 부모-자녀 간의 갈등은 청소년의 우울과 심리적 부적응을 증 가시키는 요인으로 작용하고(Jung, 2014; K.-J. Moon, 2004), 부모와의 긍정적인 관계가 이루어졌을 때 심리적 안정감을 느 
낀다고(Y. S. Park \& Kim, 2000) 보고되어왔다. 한편으로는 청 소년이 부모와의 갈등을 해결하기 위해 노력하는 것은 부모로 부터 독립하여 성인으로 이행하는 과정을 촉진시키는 힘이 된 다고 보는 시각도 있는데(Song, 1995), 청소년기의 부모-자녀 간 갈등이 가벼운 수준에서는 청소년의 심리적 발달에 긍정적 인 영향을 미친다고 보고되고 있으며(Blos, 1989; Kupersmidt, Burchinal, Leff, \& Patterson, 1992), 부모와 다소 갈등이 있다고 보고하는 청소년들이 갈등이 없다고 보고하는 집단에 비해 적 극적으로 자아정체감을 탐색하고 있음을 밝힌 연구가 있었다 (Cooper, Grotevant, Moore, \& Condon, 1982). 또한 청소년 자 녀로부터 정서적 거리 유지에 대한 요구를 받게 되는(Crouter \& Booth, 2003; White \& Klein, 2008) 청소년기 자녀를 둔 어머 니 역시 자녀와의 갈등이 심리적 안녕감에 영향을 줄 수 있는 데, 특히 어머니가 청소년 자녀와의 관계변화에 대한 심리적 준비가 이루어지지 않을 경우 외로움, 우울감 등과 같은 부정 적 정서가 증가할 수 있으며, 정신건강 상의 문제들이 나타날 가능성이 있다(Bekhet, Zauszniewski, \& Nakhla, 2008).

한편, 청소년 자녀와 어머니의 심리적 안녕감에 영향을 미 치는 모-자녀 의사소통과 갈등의 영향력을 보다 명확하게 이 해하기 위해서는 어느 한쪽이 인지한 의사소통과 갈등뿐 아니 라, 양자가 각각 인지한 의사소통과 갈등이 어떠한 역할을 수 행하며, 상호 간에 주는 영향력이 어떠한지를 확인할 필요가 있다. 오랜 시간 함께하면서 서로의 감정, 인지, 행동에 의해 영 향을 받는 관계를 상호의존성이 있는 관계라고 하는데, 이러 한 상호의존성이 있는 두 사람을 관측했을 때 관측된 값은 상 호관련성을 갖는 특징을 보일 수 있다(Kelley \& Thibaut, 1978; Kelley et al., 2003). 또한 이러한 커플자료를 독립적으로 다룰 경우 커플의 상호 역동을 알기 힘들다는 문제가 있다(Kenny, 1996). 따라서 상호관련성을 갖는 대상을 연구를 할 때는 자료 가 커플 단위(예: 어머니와 자녀가 하나의 단위)로 수집되어야 하며, 자기-상대방 상호의존모델(APIM)을 통해 자료를 분석하 는 것이 적합하다(Kenny, 1996; Kenny, Kashy, \& Bolger, 1998). 자기-상대방 상호의존 모델(APIM; Cook \& Kenny, 2005)은 상호의존적 관계에 있는 양자 간의 특성을 고려한 분석방법 (Ponnet et al., 2013)으로 이 방법을 사용하면 변인 간 관계에서 스스로의 영향(자기효과: actor effect)과 상대방으로부터의 영 향(상대방효과: partner effect)을 함께 이해할 수 있다.

또한, 청소년기에는 남녀의 신체적 구분이 뚜렷해지고, 심 리적 특성에 차이가 생기며(S. H. Shin et al., 2014), 어머니의 입장에서도 아들 혹은 딸에 대한 차별적 기대나 선호는 부모자녀 간 상호작용에 영향을 미칠 수 있기 때문에(S. Lee, Kim,
\& Lee, 2006; S. K. Moon, 2005; Warner \& Steel, 1999) 경로에서 의 성차를 살펴볼 필요가 있다. 국내 연구에서는 모-자녀 의사 소통의 경우 남학생이 여학생보다 더 긍정적으로 인지하나(J. $\operatorname{Lim} \&$ Chun, 2012), 가족관계에서의 갈등은 남학생이 더 높 고, 심리·사회적 웰빙은 여학생이 더 높은 것으로 보고된 바 있 다(H. J. Choi, 2016). 이러한 선행연구의 결과들을 토대로 어 머니와 청소년 자녀가 지각한 모-자녀 의사소통과 갈등이 이 들의 심리적 안녕감에 상호적인 영향을 미칠 수 있으며, 경로 에서의 성차가 나타날 수 있음을 가정할 수 있다. 그러나 지금 까지 어머니와 청소년 자녀 간의 의사소통과 갈등, 심리적 안 녕감에 대해 다룬 연구들은 대부분 어머니와의 의사소통이나 갈등이 자녀의 심리 、 정서적 발달에 미치는 일방향적 영향을 중심으로 연구되어 오거나, 어머니와 자녀 중 한쪽의 측정만 으로 연구되어 온 경향이 있다. 따라서, 본 연구는 어머니와 청 소년 자녀가 지각한 모-자녀 간 의사소통이 갈등을 통해 심리 적 안녕감에 미치는 자기-상대방효과를 살펴보고, 경로에서 의 성차를 확인하는 것을 목적으로 하였다. 이에 따른 연구문 제 및 연구모형은 다음과 같다(Figure 1).

\section{연구문제 1}

어머니와 남녀 청소년 자녀의 의사소통이 모-자녀 간 갈등을 통해 심리적 안녕감에 미치는 자기-상대방효과는 어떠한가?

\section{연구문제 2}

어머니와 청소년 자녀의 의사소통이 모-자녀 갈등을 통해 심 리적 안녕감에 미치는 자기-상대방효과에서 남녀 청소년 간 의 차이가 있는가?

\section{Methods}

\section{연구대상}

본 연구의 대상은 전국의 만 13-16세 청소년과 그들의 어머 니 총 249쌍(498명)이었다. 연구대상 중 청소년의 성별은 남 자가 116 명(46.6\%), 여자가 133명(53.4\%)이었으며, 평균연 령은 14.5세(최소값: 13 최대값: 16 , 표준편차: .98)였다. 어 머니의 평균연령은 44.3세(최소값: 35 최대값 57, 표준편차: 3.7)였으며, 취업모(144명, 57.8\%)가 비취업모(105명, 42.2\%) 에 비해 조금 더 많았다. 어머니의 학력은 대학교 졸업(116 명, 46.6\%), 전문대 졸업(61명, 24.5\%), 고등학교 졸업(49명, 


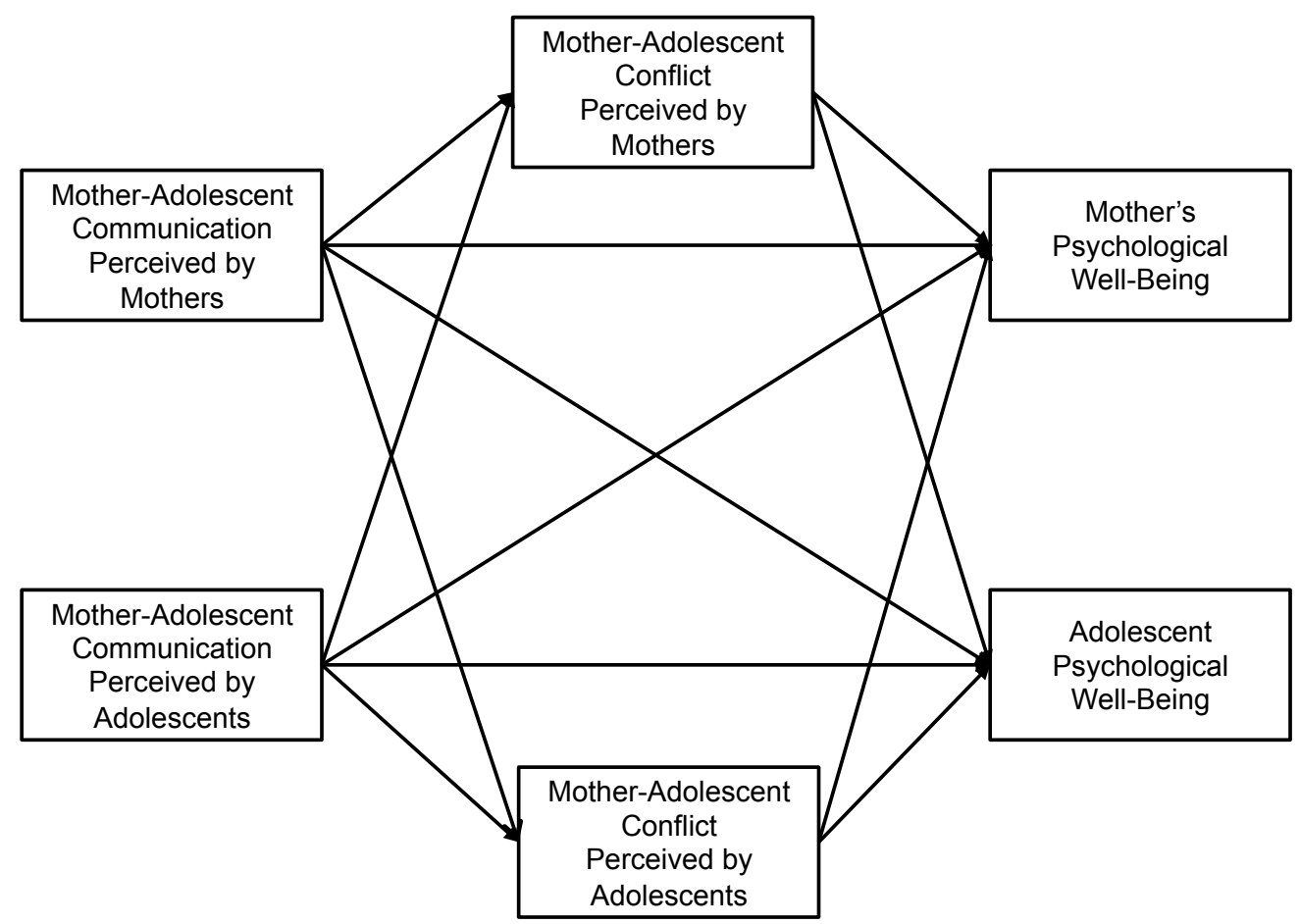

Figure 1. Indirect actor and partner effects of mother-adolescent communication on psychological well-being for mothers and adolescents via mother-adolescent conflict.

$19.7 \%)$, 대학원 졸업 이상(22명, $8.8 \%)$, 중학교 졸업(1명, $0.4 \%)$ 순으로 나타났으며, 가구월소득은 430-590만원(30.1\%), 590950만원(28.9\%), 300-430만원(16.1\%), 135-300만원(16.1\%), 950만원 이상(5.2\%), 135만원 미만(3.6\%)순으로 높게 나타났 다. 가구의 구성형태는 대부분이 부부 + 자녀(214가구, 85.9\%) 로 구성되었으며, 그 다음은 조부모 + 부부 + 자녀(20가구, $8.0 \%)$ 와 한부모 + 자녀(12가구, $4.8 \%$ ) 순으로 나타났다.

\section{연구도구}

$$
\text { 모-자녀 의사소통 척도 }
$$

모-자녀 의사소통은 Barnes와 Olson (1982)이 제작하고 Olson 등(1982)이 타당화한 부모-청소년 의사소통 척도(ParentAdolescent Communication Inventory [PACI])를 Min (1991)이 부 모용과 자녀용으로 번안한 것을 어머니용과 자녀용으로 수정 하여 사용하였다. 척도는 총 20 문항으로 이루어져 있으며, 하 위영역은 개방적 의사소통과 폐쇄적 의사소통으로 각 10 문항 씩 구성되어 있다. 개방적 의사소통은 모-자녀 간에 의사소통 을 함에 있어 자유롭게 자신의 감정을 의사를 표현할 수 있는 긍정적 측면을 측정하며, 폐쇄적 의사소통은 모-자녀 간에 의
사소통이 원활히 이루어지지 않는 부정적인 측면을 측정한다. 어머니용 문항의 예로는 "나의 소신을 자녀와 거리낌 없이 의 논할 수 있다.”, 자녀용 문항의 예로는 "어머니는 내 말을 늘 귀 담아 들어준다.” 등이 있다. 각 문항은 5점 Likert척도로 구성되 어 있고, 폐쇄적 의사소통의 문항을 역채점한 후, 전체 20 문항 의 평균값을 사용하였으며, 점수가 높을수록 어머니와 자녀 간 에 개방적으로 의사소통을 하는 것으로, 점수가 낮을수록 폐쇄 적으로 의사소통을 하는 것으로 보았다. 문항 간 내적 합치도 는(Cronbach' $\alpha$ ) 어머니가 인지한 모-자녀 의사소통이 .90 , 청소 년 자녀가 인지 한 모-자녀 의사소통이 .92로 나타났다.

$$
\text { 모-자녀 갈등 척도 }
$$

모-자녀 간 갈등을 측정하기 위하여 Prinz, Foster, Kent와 O'Leary (1979)가 개발하고 타당화한 모-자녀 간 불평 및 불만 척도(Conflict Behavior Questionnaire [CBQ])를 Hwang과 Doh (2004)가 번안한 척도를 사용하였다. 본 척도는 상대방에 대 한 불평 및 불만에 대한 28 문항과 모-자녀 간 상호작용에 대한 불평 및 불만에 대한 16 문항, 총 44 문항으로 구성되며, 어머니 보고용과 청소년 보고용으로 나누어져 있다. 어머니 보고용 문항의 예로는 “우리 아이는 나에게 말을 함부로 한다.”가 있 
으며, 청소년 보고용 문항의 예로는 "어머니와 나는 의견이 서 로 일치하는 경우가 별로 없다.” 등이 있다. $\mathrm{CBQ}$ 는 부정적인 문항에서 “예”라고 답한 문항의 수와 긍정적인 문항에서 “아 니오”라고 답한 문항의 수를 합산하여 0 44점까지 산출이 가 능하고, 점수가 높을수록 어머니와 자녀 간에 갈등이 높은 것 을 의미한다. 문항 간 내적 합치도는(Cronbach' $\alpha$ ) 어머니가 인 지한 모-자녀 갈등이 .91, 청소년 자녀가 인지한 모-자녀 갈등 이 .91로 나타났다.

\section{심리적 안녕감 척도}

어머니와 청소년 자녀의 심리적 안녕감을 측정하기 위하여 Keyes 등(2008)이 개발한 단축형 정신건강 척도를 Y.-J. Lim, Ko, Shin과 Cho (2012)가 번역하고 타당화한 한국형 정신 건강 단축척도(Korean Mental Health Continum Short-Form [K-MHC-SF]) 중 심리적 웰빙을 측정하는 6 문항을 사용하였 다. 문항의 예로는 "매일의 생활에서 내가 해야 할 책임들을 잘 해내고 있다고 느꼈다.", "다른 사람들과 따뜻하고 신뢰로 운 관계를 맺고 있다고 느꼈다.” 등이 있다. 응답자들은 6점 Likert척도로 응답하였다. 어머니와 청소년 자녀 모두 동일한 척도를 사용하여 측정하며, 총점이 높을수록 심리적 안녕감의 수준이 높은 것을 의미한다. 문항 간 내적 합치도는(Cronbach' $\alpha$ ) 어머니의 심리적 안녕감은 .86, 청소년의 심리적 안녕감은 .88로 나타났다.

\section{통제변인}

본 연구에서는 가구의 사회경제적 수준(Chae \& Hwang, 2014; S.-Y. Park \& Lee, 2013; E.-M. Yeon, Yoon, \& Choi, 2016), 어머 니의 취업여부(Jo \& Cho, 2004), 가구형태(Bigner, 1989)와 청 소년의 연령(Bae, 1999; H. J. Choi, 2016)이 연구변인들 간의 관계에 영향을 미칠 수 있다는 선행연구를 근거로 경로모형을 검증할 때 사회경제적 수준(월가구소득, 모학력), 모취업여부, 한부모/양부모 여부, 청소년의 연령을 통제하였으며, 연구의 결과는 통제 후의 결과만 보고하였다.

\section{연구절차}

본 연구의 연구대상인 만13-16세 청소년과 어머니 249쌍은 온 라인 리서치 업체(패널나우)에 의뢰하여, IRB 승인일인 2020 년 7월 13일부터 2020년 8월 11일까지 설문을 진행하였다. 이
를 위해 연구참여 설명서와 설문지를 온라인 리서치 업체에 보냈으며, 리서치 업체에서는 미성년 자녀가 있는 여성을 대 상으로 설문 안내 메일을 발송하여 참여자가 연구대상에 적합 한지를 판별한 후 대상자를 스크리닝하였다. 이후 연구에 대 한 설명문을 읽고 이에 동의하여, 어머니가 어머니용 설문에 대해 동의하고, 자녀용 설문에 대해 청소년과 어머니(법정대 리인)가 모두 동의하여, 전자서명을 한 참여자들에 한해 온라 인 설문을 진행하였다.

\section{자료분석}

본 연구에서는 수집된 자료를 SPSS 23.0 (IBM Co., Armonk, $\mathrm{NY}$ )과 AMOS 23.0 (IBM Co., Armonk, NY) 프로그램을 통해 분석하였다. 먼저 연구대상의 인구통계학적 특성을 알아보기 위해 빈도분석과 기술통계를 실시하였으며, 연구변인들 간의 관계를 알아보기 위해 Pearson의 상관관계 분석을 실시하였 다. 청소년과 어머니가 인지한 모-자녀 의사소통이 모-자녀 갈 등을 통해 심리적 안녕감에 미치는 자기-상대방효과를 알아 보기 위하여 남/녀 집단을 구분하여 경로모형분석(path model analysis)을 하였으며, 경로에서의 성차를 알아보기 위해 다중 집단 경로분석을 실시하고, 간접효과의 유의성을 확인하기 위 하여 부트스트레핑(bootstrapping)방법을 사용하였으며, 다중 의 매개효과를 구분하여 살펴보기 위하여 팬텀변수(phantom variable)를 활용하여 개별간접효과(specific indirect effect)를 추 정하였다(Ledermann, Macho, \& Kenny, 2011). 한편, 경로모형 검증 시 사회경제적 수준(월가구소득, 모학력), 모취업여부, 한부모/양부모 여부, 청소년의 연령을 통제하였다.

\section{Results}

\section{기술통계 및 상관분석}

본 연구의 주요 변인인 어머니와 청소년 자녀가 인지한 모-자 녀 의사소통, 모-자녀 갈등, 심리적 안녕감의 일반적 경향성과 정규분포 가정 충족 여부를 확인하기 위하여 평균, 표준편차, 왜도와 첨도를 산출하였으며, 정규성에 문제가 없음을 확인하 였다(Table 1). 또한 연구변인들 간의 관계을 알아보기 위하여 Pearson의 상관계수를 산출한 결과 모든 변인들 간에 유의한 상관이 있는 것으로 나타났다(Table 2). 
Table 1

Descriptive Statistics Among Variables

\begin{tabular}{|c|c|c|c|c|c|c|c|}
\hline & Variables & $M$ & Min & Max & $S D$ & Skewness & Kurtosis \\
\hline \multirow[t]{2}{*}{ Mother } & Mother-adolescent communication & 3.73 & 2.25 & 5.00 & .53 & -.24 & -.63 \\
\hline & Mother-adolescent conflict & 8.64 & .00 & 37.00 & 7.63 & 1.49 & 2.01 \\
\hline \multirow[t]{2}{*}{ Adolescents } & Mother-adolescent communication & 3.71 & 2.25 & 5.00 & .61 & -.21 & -.71 \\
\hline & Mother-adolescent conflict & 8.33 & .00 & 34.00 & 7.61 & 1.14 & .85 \\
\hline
\end{tabular}

Note. $N=249$ dyads.

Table 2

Correlation Coefficients Among Variables

\begin{tabular}{|c|c|c|c|c|c|c|c|}
\hline & & 1 & 2 & 3 & 4 & 5 & 6 \\
\hline \multirow[t]{3}{*}{ Mother } & Mother-adolescent communication & - & & & & & \\
\hline & Mother-adolescent conflict & $-.69^{* * *}$ & - & & & & \\
\hline & Psychological well-being & $.33^{* * *}$ & $-.28^{* * *}$ & - & & & \\
\hline \multirow[t]{3}{*}{ Adolescent } & Mother-adolescent communication & $.73^{* * *}$ & $-.63^{* * *}$ & $.30^{* * *}$ & - & & \\
\hline & Mother-adolescent conflict & $-.54^{* * *}$ & $.77^{* * *}$ & $-.31^{* * *}$ & $-.73^{* * *}$ & - & \\
\hline & Psychological well-being & $.37^{* * *}$ & $-.38^{* * *}$ & $.54^{* * *}$ & $.45^{* * *}$ & $-.39^{* * *}$ & - \\
\hline
\end{tabular}

Note. $N=249$ dyads. 1 = Mother's perception of mother-adolescent communication; 2 = Mother's perception of mother-adolescent conflict; 3 = Mother's psychological well-being; 4 = Adolescent perception of mother-adolescent communication; $5=$ Adolescent perception of mother-adolescent conflict; 6 = Adolescent psychological well-being.

*** $p<.001$.

어머니와 남자 청소년 자녀가 인지한 모-자녀 의사소통이 모-자녀 갈등을 통해 심리적 안녕 감에 미치는 자기-상대방효과

어머니와 남자 청소년 자녀가 인지한 모-자녀 의사소통과 심 리적 안녕감 간의 관계에서 어머니와 남자 청소년 자녀가 인 지한 모-자녀 갈등의 매개효과를 알아보기 위하여 경로분석 을 실시하였다. 모형의 적합도는 $\chi^{2}=14.74, d f=10, p<.14$, $\mathrm{GFI}=.98, \mathrm{NFI}=.97, \mathrm{TLI}=.94, \mathrm{CFI}=.99, \mathrm{RMSEA}=.06$ 으로 양호하게 나타났다. 먼저 직접효과를 살펴보면, 자기효과의 경우 어머니가 인지한 모-자녀 의사소통이 어머니가 인지한 모-자녀 갈등에 부적 영향을 미쳤고 $(\beta=-.49, p<.001)$, 자녀 가 인지한 모-자녀 의사소통은 자녀가 인지한 모-자녀 갈등( $\beta$ $=-.79, p<.001)$ 에 부적 영향을, 자녀가 인지한 심리적 안녕감 $(\beta=.33, p<.05)$ 에 정적 영향을 미쳤다. 또한 어머니가 인지한 모-자녀 갈등은 어머니의 심리적 안녕감에 부적 영향 $(\beta=-.47$, $p<.001)$ 을, 자녀가 인지한 모-자녀 갈등은 자녀의 심리적 안 녕감에 정적 영향 $(\beta=.39, p<.05)$ 을 미쳤다. 상대방효과의 직 접효과를 살펴보면, 청소년이 인지한 모-자녀 의사소통은 어
머니가 인지한 모-자녀 갈등에 부적 영향을 미쳤고 $(\beta=-.28, p$ $<.01)$, 어머니가 인지한 모-자녀 갈등은 청소년의 심리적 안녕 감에 부적 영향을 미쳤다 $(\beta=-.60, p<.001)$. 다음으로 어머니 와 자녀가 인지한 모-자녀 의사소통이 어머니와 자녀의 심리 적 안녕감에 미치는 매개효과를 간접적 자기효과와 간접적 상 대방효과로 나누어 살펴보았다(Muraru \& Turlluc, 2015). 부트 스트레핑(bootstrapping)을 통한 간접효과의 유의성은 Table 3 과 같다.

어머니와 여자 청소년 자녀가 인지한 모-자녀 의사소통이 모-자녀 갈등을 통해 심리적 안녕 감에 미치는 자기-상대방효과

어머니와 여자 청소년 자녀가 인지한 모-자녀 의사소통과 심 리적 안녕감의 관계에서 어머니와 여자 청소년 자녀가 인지한 모-자녀 갈등의 매개효과를 알아보기 위하여 경로분석을 실 시하였다. 모형의 적합도는 $\chi^{2}=10.07, d f=10, p<.44, \mathrm{GFI}=$ $.99, \mathrm{NFI}=.98, \mathrm{TLI}=1.00, \mathrm{CFI}=1.00, \mathrm{RMSEA}=.01$ 로 양호하 게 나타났다. 먼저 직접효과를 살펴보면 자기효과의 경우 모 
Table 3

Indirect Actor-Partner Effects of Mother-Child Communication on Psychological Well-being via Mother-Child Conflict in Mother-Child (Boys) Dyads Path $\beta$

Indirect actor effect

Communication perceived by mothers

$\rightarrow$ Conflict perceived by mothers $\rightarrow$ Mother's well-being

$.40^{* * *}$

Communication perceived by mothers

$\rightarrow$ Conflict perceived by adolescents $\rightarrow$ Mother's well-being

.02

Communication perceived by adolescents

$\rightarrow$ Conflict perceived by adolescents $\rightarrow$ Adolescent well-being

$-.48^{* * *}$

Communication perceived by adolescents

$\rightarrow$ Conflict perceived by mothers $\rightarrow$ Adolescent well-being

$.27^{* * *}$

Indirect partner effect

Communication perceived by adolescents

$\rightarrow$ Conflict perceived by adolescents $\rightarrow$ Mother's well-being

$-.23$

Communication perceived by adolescents

$\rightarrow$ Conflict perceived by mothers $\rightarrow$ Mother's well-being

Communication perceived by mothers

$\rightarrow$ Conflict perceived by mothers $\rightarrow$ Adolescent well-being

Communication perceived by mothers

$\rightarrow$ Conflict perceived by adolescents $\rightarrow$ Adolescent well-being

Note. $N=116$ dyads

*** $p<.001$.

두 유의한 것으로 나타났다. 구체적으로, 어머니가 인지한 모자녀 의사소통은 어머니가 인지한 모-자녀 갈등에 부적 영향 을 미쳤고 $(\beta=-.53, p<.001)$, 어머니의 심리적 안녕감에는 정 적 영향을 미쳤으며 $(\beta=.39, p<.01)$, 여자 청소년 자녀가 인 지한 모-자녀 의사소통은 여자 청소년 자녀가 인지한 모-자녀 갈등에 유의한 부적 영향 $(\beta=-.64, p<.001)$ 을, 여자 청소년의 심리적 안녕감에는 유의한 정적 영향을 $(\beta=.35, p<.01)$ 미치 는 것으로 나타났다. 또한 어머니가 인지한 모-자녀 갈등은 어 머니의 심리적 안녕감에 정적 영향을 $(\beta=.31, p<.05)$ 주었으 며, 여자 청소년 자녀가 인지한 모-자녀 갈등은 여자 청소년 의 심리적 안녕감에 유의한 부적 영향 $(\beta=-.32, p<.05)$ 을 미쳤 다. 상대방효과의 직접효과를 보면, 여자 청소년 자녀가 인지 한 모-자녀 의사소통이 어머니가 인지한 모-자녀 갈등에 부적 영향 $(\beta=-.22, p<.05)$ 을 주었으며, 여자 청소년 자녀가 인지한 모-자녀 갈등은 어머니의 심리적 안녕감에 부적 영향 $(\beta=-.37$, $p<.01$ )을 주었다. 부트스트레핑(bootstrapping)을 통한 간접효 과의 유의성은 Table 4 와 같다.

\section{다중집단 경로분석}

본 연구의 경로모형이 청소년의 성에 따라 차이가 있는지 검
증하기 위하여 다중집단 경로분석을 실시하였다. 먼저 형태 동일성 가정을 만족하는지를 확인하기 위하여 모형의 적합도 지수를 살펴본 결과, 남자 청소년 집단에서는 $\chi^{2}=14.74, d f=$ $10, p=.142, \mathrm{NFI}=.97, \mathrm{IFI}=.99, \mathrm{CFI}=.99, \mathrm{RMSEA}=.064$, 여 자 청소년 집단에서는 $\chi^{2}=10.07, d f=10, p=.435, \mathrm{NFI}=.98$, $\mathrm{IFI}=1.00, \mathrm{CFI}=1.00, \mathrm{RMSEA}=.008$ 로 나타났다. 두 집단 모 두 적합도 지수가 양호하므로 형태 동일성 가정이 만족함을 알 수 있었다. 다음으로 측정 동일성 가정 충족 여부를 살펴보 았다. 측정 동일성 가정 확인을 위해 두 그룹에서 통제변수를 제외한 외생변수의 공분산과 내생변수의 오차 분산에 동일성 제약을 가한 모형과 제약을 가하지 않은 자유모형 간에 카이 제곱차이 검증을 실시하였다. 분석결과, 두 모형 간에는 적합 도가 유의미한 차이가 없는 것으로 나타나 $\left(\chi^{2}=5.48, d f=5, n s\right)$ 측정 동일성 가정이 만족함을 확인하였다. 형태 동일성과 측 정 동일성 가정을 만족하였으므로 경로계수가 집단 간 차이가 있는지 검증하기 위하여 모든 경로를 제약한 모델과 아무것도 제약하지 않은 모델의 카이제곱 변화량 값의 통계적 유의성을 살펴보았다(Yu, 2012). 두 모델을 비교한 결과 통계적으로 유 의한 차이가 나타나 $\left(\chi^{2}=31.21, d f=12, p<.01\right)$ 남자 청소년과 여자 청소년 집단 간 경로의 차이가 있다고 판단하였다. 구체 적으로 어느 경로에서 차이가 나타나는지를 확인하기 위하여 
Table 4

Indirect Actor-Partner Effects of Mother-Child Communication on Psychological Well-being via Mother-Child Conflict in Mother-Child (Girls) Dyads Path $\beta$

Indirect actor effect

Communication perceived by mothers

$\rightarrow$ Conflict perceived by mothers $\rightarrow$ Mother's well-being

Communication perceived by mothers

$\rightarrow$ Conflict perceived by adolescents $\rightarrow$ Mother's well-being

Communication perceived by adolescents

$\rightarrow$ Conflict perceived by adolescents $\rightarrow$ Adolescent well-being

Communication perceived by adolescents

$\rightarrow$ Conflict perceived by mothers $\rightarrow$ Adolescent well-being

Indirect partner effect

Communication perceived by adolescents

$\rightarrow$ Conflict perceived by adolescents $\rightarrow$ Mother's well-being

Communication perceived by adolescents

$\rightarrow$ Conflict perceived by mothers $\rightarrow$ Mother's well-being

Communication perceived by mothers

$\rightarrow$ Conflict perceived by mothers $\rightarrow$ Adolescent well-being

Communication perceived by mothers

$\rightarrow$ Conflict perceived by adolescents $\rightarrow$ Adolescent well-being

Note. $N=133$ dyads.

${ }^{*} p<.05$.

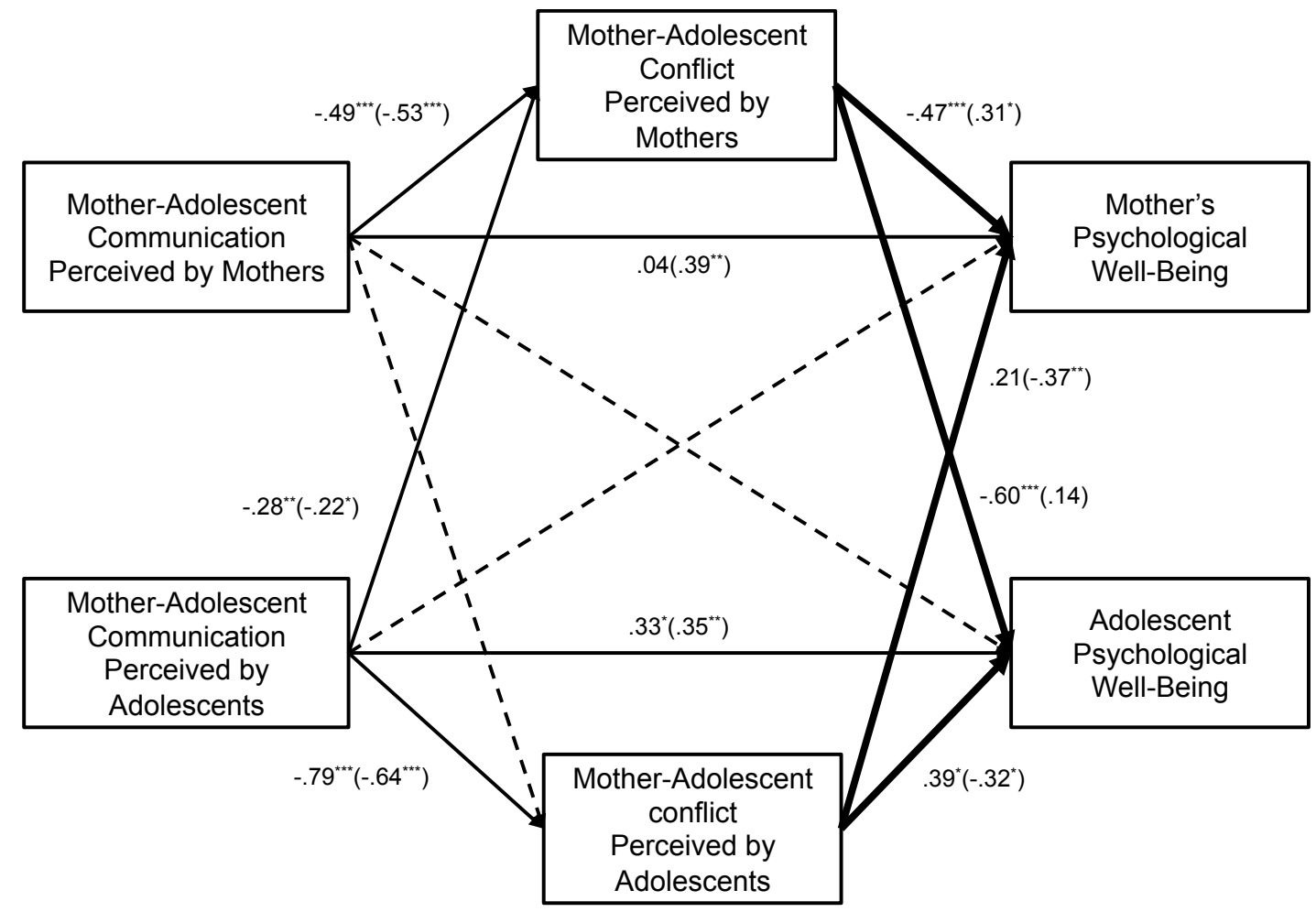

Figure 2. Difference in path coefficient according to adolescent gender (Standardized regression coefficient). The control variables were omitted. The figures in parentheses are the female adolescent group, and the bold path is the path with significant differences between the groups.

${ }^{* * *} p<.001{ }^{* *} p<.01 .^{*} p<.05$. 
Table 5

Test for Invariance in Path Coefficients Across Groups (Boys and Girls)

\begin{tabular}{lcccccc}
\hline \multicolumn{1}{c}{ Model } & $\chi^{2}$ & $d f$ & IFI & CFI & RMSEA & $\chi^{2}$ test \\
\hline Standard Model & 24.81 & 20 & 1.00 & 1.00 & .031 & - \\
Communication perceived by mothers $\rightarrow$ Conflict perceived by mothers & 24.82 & 21 & 1.00 & 1.00 & .027 & $\chi^{2}(1)=.01, n s$ \\
Communication perceived by mothers $\rightarrow$ Mother's well-being & 27.94 & 21 & 1.00 & 1.00 & .037 & $\chi^{2}(1)=3.13, n s$ \\
Communication perceived by mothers $\rightarrow$ Adolescent well-being & 24.81 & 21 & 1.00 & 1.00 & .027 & $\chi^{2}(1)=.00, n s$ \\
Communication perceived by mothers $\rightarrow$ Conflict perceived by adolescents & 25.97 & 21 & 1.00 & 1.00 & .031 & $\chi^{2}(1)=1.17, n s$ \\
Conflict perceived by mothers $\rightarrow$ Mother's well-being & 38.03 & 21 & .98 & .98 & .057 & $\chi^{2}(1)=13.22, p<.001$ \\
Conflict perceived by mothers $\rightarrow$ Adolescent well-being & 37.52 & 21 & .98 & .98 & .056 & $\chi^{2}(1)=12.71, p<.001$ \\
Communication perceived by adolescents $\rightarrow$ Conflict perceived by mothers & 24.94 & 21 & 1.00 & 1.00 & .028 & $\chi^{2}(1)=.13, n s$ \\
Communication perceived by adolescents $\rightarrow$ Mother's well-being & 25.56 & 21 & 1.00 & 1.00 & .030 & $\chi^{2}(1)=.76, n s$ \\
Communication perceived by adolescents $\rightarrow$ Adolescent well-being & 24.81 & 21 & 1.00 & 1.00 & .031 & $\chi^{2}(1)=.00, n s$ \\
Communication perceived by adolescents $\rightarrow$ Conflict perceived by adolescents & 28.53 & 21 & .99 & .99 & .038 & $\chi^{2}(1)=3.72, n s$ \\
Conflict perceived by adolescents $\rightarrow$ Adolescent well-being & 35.80 & 21 & .99 & .99 & .053 & $\chi^{2}(1)=10.99, p<.01$ \\
Conflict perceived by adolescents $\rightarrow$ Mother's well-being & 32.45 & 21 & .99 & .99 & .047 & $\chi^{2}(1)=7.64, p<.01$ \\
\hline
\end{tabular}

Note. $N=249$ dyads.

${ }^{* *} p<.01 .{ }^{* * *} p<.001$.

각 경로별로 동일성 제약을 가하여 카이제곱차이 검증을 실시 하였고 그 결과를 Table 5에 제시하였다. 분석결과, 어머니가 지각한 모-자녀 갈등이 어머니의 심리적 안녕감에 미치는 영 향, 어머니가 지각한 모-자녀 갈등이 자녀의 심리적 안녕감에 미치는 영향, 자녀가 지각한 모-자녀 갈등이 자녀의 심리적 안 녕감에 미치는 영향, 자녀가 지각한 모-자녀 갈등이 어머니의 심리적 안녕감에 미치는 영향에서의 차이가 유의미한 것으로 나타났다. 각 집단 간 경로계수를 Figure 2에 제시하였다.

\section{Discussion}

본 연구는 Bowen (1966)의 가족체계이론과 Cook과 Kenny (2005)의 자기-상대방 상호의존모델을 기초로, 어머니와 남녀 청소년 자녀가 인지한 모-자녀 의사소통이 모-자녀 갈등을 통 해 심리적 안녕감에 미치는 자기-상대방효과와 성차를 알아 보았다. 주요 연구결과를 다음과 같이 요약하고 논의하였다.

첫째, 어머니와 남자 청소년 자녀가 인지한 모-자녀 의사소 통이 모-자녀 갈등을 통해 심리적 안녕감에 미치는 자기-상대 방효과에서 부분적으로 간접적 자기효과와 간접적 상대방효 과가 나타났다. 먼저 간접적 자기효과를 살펴보면, 어머니는 남자 청소년 자녀와의 의사소통을 개방적이라고 인지할수록 갈등을 낮게 인지하였고, 이를 통해 심리적 안녕감이 높아졌다. 이러한 본 연구의 결과는 남자 청소년 자녀의 어머니가 인지한
모-자녀 간 의사소통이 모-자녀 갈등에 부적 영향을 주며(Y.-H. Chun \& Ko, 2005), 모-자녀 갈등이 어머니의 심리적 안녕감에 부적인 영향을 주었다고 보고한(O. N. Kim, 2004; T. Kim \& Ki, 2019) 선행연구 결과들과 부분적으로 일치한다. 즉, 어머니의 입장에서 아들과 다양한 주제로 자유롭게 대화한다고 인식하 는 것은 자녀와의 갈등을 줄이는 역할을 하고, 이를 통해 높은 심리적 안녕감을 느낄 수 있는 것으로 해석할 수 있다.

또한 남자 청소년의 경우 모-자녀 의사소통을 개방적으로 인지할수록 갈등을 낮게 인지하였으나, 이를 통해 심리적 안 녕감이 낮아졌다. 이러한 결과는 부모-자녀 간 의사소통이 개 방적일수록 갈등이 적었다고 보고한 다수의 선행연구 결과 들(Y.-H. Chun \& Ko, 2005; Kong, Yi, \& Lee, 2005; M.-S. Park, $\mathrm{Cha}, \& \mathrm{Kim}, 2014)$ 과 맥락을 같이 하나, 청소년이 인지한 가족 간 갈등이 우울, 비행 및 문제행동 등에 부정적인 영향을 미친 다고 보고한 선행연구의 결과들(Y. Kim \& Ahn, 2008)과는 대 비되는 결과이다. 그러나 상호협력적 관계에서는 갈등의 과정 이 건설적으로 이루어질 수 있으며(Deutsch, 1994), 갈등이 낮 은 수준에서는 청소년의 심리적 변인에 긍정적 영향을 줄 수 있다고 보고되어왔다(Blos, 1989; Kupersmidt et al., 1992). 따라 서 본 연구의 결과는 모-자녀 갈등 변인의 값이 낮은 것에 기 인할 가능성이 있으며, 남자 청소년들은 어머니와의 상호작용 속에서 발생한 갈등을 스트레스 상황으로 인식하기보다는 자 신이 사회의 구성원으로서 긍정적으로 기능하기 위해 필요한 과정으로 인식한 것으로 해석할 수 있다. 
한편, 남자 청소년이 모-자녀 의사소통을 개방적으로 느낄 수록 어머니가 모-자녀 갈등을 낮게 인지하였으며, 이를 통해 남자 청소년의 심리적 안녕감이 높아졌다. 앞서 남자 청소년 자녀가 모-자녀 갈등을 높게 인지할수록 남자 청소년의 심리 적 안녕감이 높았던 결과와 달리, 어머니가 모-자녀 갈등을 높 게 인지하는 것은 남자 청소년 자녀의 심리적 안녕감을 낮추 는 상반되는 역할을 한 것이다. 이는 같은 상황을 경험하더라 도 그 경험에 대한 상대방의 인식에 따라 개인의 심리적 변인 에 대한 영향력이 다를 수 있음을 시사한다.

다음으로 간접적 상대방효과를 살펴보면, 남자 청소년 자 녀가 모-자녀 의사소통을 개방적이라고 인지할수록 어머니가 인지한 모-자녀 갈등이 낮아졌으며, 이는 어머니의 심리적 안 녕감을 높였다. 이러한 결과는 어머니가 자녀와의 갈등을 인 지함에 있어 의사소통에 대한 아들의 인식에 영향을 받음을 시사한다. 마지막으로, 어머니가 모-자녀 의사소통을 개방적 으로 인지할수록 어머니가 인지한 모-자녀 갈등이 낮았으며, 이는 남자 청소년의 심리적 안녕감을 높였다. 이러한 결과는 남자 청소년의 경우, 자신의 어머니가 자녀와 의사소통이 자 유롭고 원활하게 이루어진다고 인식하고, 이를 통해 자녀와 갈등이 적다고 인식하는 것에 의미를 두고 있다는 것을 시사 하며, 이러한 어머니의 인식을 자신이 사회의 구성원으로서 잘 기능하고 있는지를 가늠하는 하나의 도구로 사용한다는 것 을 보여준다.

둘째, 어머니와 여자 청소년이 인지한 모-자녀 의사소통이 모-자녀 갈등을 통해 심리적 안녕감에 미치는 자기-상대방효 과는 간접적 자기효과와 간접적 상대방효과가 부분적으로 유 의한 것으로 나타났다. 우선 간접적 자기효과를 살펴보면, 여 자 청소년 자녀의 경우 어머니와의 의사소통을 개방적이라고 인지할수록 모-자녀 갈등을 낮게 인지하였고, 이는 심리적 안 녕감을 높이는 역할을 하였다. 이러한 결과는 부모와의 의사 소통이 개방적이라고 인식할수록 부모와의 갈등이 적었으며 (Kong, Yi, \& Lee, 2005; M.-S. Park, Cha, \& Kim, 2014), 모-자녀 갈등은 청소년의 심리적 안녕감에 부정적인 영향을 미친다고 보고한 선행연구(O. N. Kim, 2004)의 결과들을 지지한다. 다 음으로, 간접적 상대방효과를 살펴보면 여자 청소년 자녀가 모-자녀 의사소통을 개방적이라고 인지할수록 자녀가 인지한 모-자녀 갈등이 낮았으며, 이는 어머니의 심리적 안녕감을 높 이는 데 영향을 주었다. 이러한 결과는 어머니가 심리적 안녕 감을 판단함 있어 여자 청소년 자녀의 모-자녀 관계에 대한 인 식을 중요하게 생각하는 것으로 해석할 수 있다. 또한, 여자 청 소년 자녀가 인지한 모-자녀 의사소통이 개방적일수록 어머
니는 자녀와의 갈등을 낮게 인지하였고, 이는 어머니의 심리 적 안녕감을 낮아지게 하는 역할을 하였다. 이러한 본 연구의 결과는 어머니가 여자 청소년 자녀와 폐쇄적으로 의사소통 을 할수록 모-자녀 갈등이 커진다고 보고한 선행연구 결과(Y.H. Chun \& Ko, 2005)와 부분적으로 맥락을 함께하나, 자녀와 의 갈등이 우울과(O. N. Kim, 2004; T. Kim \& Ki, 2019) 심한 스트레스를 유발한다고 보고한 선행연구(Hagerty \& Williams, 1999)의 결과들과는 대조적이다. 그러나 자녀와의 관계에서 친밀감이 낮아지고 분리감이 높아질수록 중년기의 우울이 증 가하며(H.-K. Park \& Choi, 2012), 어머니가 인지한 자녀와의 공격적 갈등 유형과 자녀와의 친밀감 간에 정적상관이 있다고 보고한 선행연구(Sonja, 2016)의 결과를 고려하였을 때, 모-자 녀 갈등은 비록 모-자녀 간에 상대방이나 상대방과의 의사소 통에 대해 불평과 불만을 많이 가진다고 할지라도, 기본적으 로 잦은 상호작용을 통한 친밀감을 바탕으로 하기 때문에 이 를 통해 갈등을 해결하는 방법을 고민하고, 서로 간의 친밀감 을 확인하는 과정을 거친다면, 어머니의 심리적 안녕감에 긍 정적인 영향을 주는 것으로 해석할 수 있다. 특히 어머니와 딸 의 경우 가족관계 중 가장 친밀한 관계로 알려져 있기 때문에, 딸과의 분리감은 어머니의 심리적 안녕감에 부정적 영향을 미 쳤을 것으로 보인다.

셋째, 어머니와 청소년 자녀가 인지한 모-자녀 의사소통이 모-자녀 갈등을 통해 심리적 안녕감에 미치는 자기-상대방효 과에서 성차가 나타났다. 먼저 자기효과를 살펴보면, 어머니 는 아들과의 갈등이 높을수록 심리적 안녕감이 낮았던 반면, 딸과의 갈등은 어머니의 심리적 안녕감에 긍정적인 영향을 주 었다. 이러한 성차는 어머니와 자녀 간에 나타나는 갈등의 양 상이 성에 따라 다르기 때문으로 예측해볼 수 있다. 선행연구 에서는 일관적으로 남학생들이 부모의 간섭에 더 민감하게 반 응하고(Keum, Kim, \& Kim, 2002; S. Lee, Lee, \& Kim, 2008; K. J. Moon \& Oh 2002), 부모에게 덜 수용적인 것으로 나타났다 (Armentrout \& Burger, 1972). 또한 여학생들은 가정 내의 문제 들(의사소통, 생활 관리, 집안일, 행동규제 등)과 연관된 갈등 이 더 많았던 반면(Seo, Jeon, An, \& Choeng, 2015), 남학생들은 진로 및 성적 등과 관련된 갈등이 높은 것으로 보고되어왔다 (Baek, 2000; H. J. Choi, 2016). 이러한 선행연구결과를 고려할 때 해당 경로에서의 성차는 어머니와의 갈등에서 주로 다루어 지는 주제와 양상에서의 성차에 따른 영향일 가능성이 있다. 다만, 본 연구에서는 갈등의 주제를 구분하지 않고, 상대방 및 상대방과의 상호작용에 대한 불평 및 불만에 대해 측정하였기 때문에, 해석이 조심스러우며 추후 연구에서는 갈등의 종류를 
구분하여 이 경로에 대한 깊이 있는 탐구를 할 필요가 있다.

또한, 청소년 자녀가 지각한 모-자녀 갈등이 청소년의 심리 적 안녕감에 미치는 영향에서, 여자 청소년의 경우 본인이 지 각한 모-자녀 갈등이 낮을수록 심리적 안녕감이 높았으나, 남 자 청소년의 경우 본인이 지각한 모-자녀 갈등이 높을수록 심 리적 안녕감이 높은 것으로 나타났다. 이러한 결과는 괴롭힘 피해와 우울 간의 관계를 부모-자녀 간 갈등이 중재하는지를 살펴본 연구(Lahav-Kadmiel \& Brunstein-Klomek, 2018)의 결과 와 맥을 함께한다. 해당 연구에서는 여아의 경우 부모-자녀 간 갈등이 높을수록 괴롭힘 피해와 우울 증상 사이의 관련성이 강 해졌으나, 남아의 경우 부모-자녀 간 갈등수준이 낮을수록 괴 롭힘 피해로 인한 우울 증상이 강해지는 것으로 나타났다. 또 한, 국내연구에서는 어머니의 과잉기대와 간섭이 여자 청소년 의 자아존중감을 낮추는 역할을 한 반면, 남자 청소년에게는 영향을 미치지 않았으며(Yoon \& Choi, 2004), 여학생은 부모에 게 애정이 느껴지지 않는다고 지각할 때, 남학생의 경우 자신 에게 부모가 신경 쓰지 않는다고 지각할 때 내재화 문제가 증 가하는 것으로 보고되었다(Jwa, 2018). 아들의 경우 가족관계 내에서 딸에 비해 친밀하고 지지적인 관계가 덜 형성되는 특성 이 있으며(S. Lee et al., 2008), 성역할 고정관념으로 인해 감정 표현에 있어서도 어려움을 겪는 경향이 있다는 측면에서(H.K. Shin, 2002), 남자 청소년이 인지한 어머니와의 갈등은 스트 레스 상황으로 인식되어 부정적 역할을 하기보다는 어머니와 의 의견대립과 격한 감정의 표출로나마 상호작용의 기회를 제 공함으로써, 심리적 안녕감을 높이는 데 도움을 주었을 가능성 이 있다. 따라서 추후 연구에서는 양육태도의 성차를 고려하여 모-자녀 갈등의 영향력을 재검토할 필요성이 있다.

다음으로 상대방효과를 살펴보면, 어머니가 지각한 모-자 녀 갈등이 자녀의 심리적 안녕감에 미치는 영향과 자녀가 지 각한 모-자녀 갈등이 어머니의 심리적 안녕감에 미치는 영향 에서 청소년의 성에 따른 차이가 나타났다. 우선, 남자 청소 년이 인지한 모-자녀 갈등은 어머니의 심리적 안녕감에 영향 을 주지 않았으나, 여자 청소년이 인지한 모-자녀 갈등은 어머 니의 심리적 안녕감에 부적 영향을 미쳤다. 이는 어머니의 입 장에서 자녀의 성에 따라 기대 수준이 다르기 때문으로 해석 할 수 있다. 일반적으로 어머니에게 있어 딸과의 관계는 아들 과의 관계보다 친밀감이나 유대감이 높은 관계로 여겨지며, 특히 심리.정서적인 지지에 있어 딸에게 더 기대가 높은 경향 이 있다. 선행연구에서도 딸이 아들보다 어머니와의 애정표현 이나 정보교환에 있어서 더 긴밀한 관계를 유지하고 있는 것 으로 나타났다(S. Lee et al., 2006). 따라서 어머니의 입장에서
정서적 지지에 대한 기대가 높은 여자 청소년이 인식하는 모자녀 갈등만이 어머니의 심리적 안녕감에 부적 영향을 주었 을 것으로 유추할 수 있다. 한편, 어머니가 인지한 모-자녀 갈 등의 상대방효과는 남자 청소년의 심리적 안녕감에만 유의하 게 나타났다. 이러한 결과는 청소년기 자녀의 심리적 변인에 있어 이성 부모의 영향력이 크다고 나타난 선행연구들(Nam, 2012; H.-K. Shin, 2002)과 맥락을 같이 하며, 청소년기에 증가 하는 이성에 대한 관심이 이성의 역할모델이 되는 이성 부모 에 대한 관심으로 이어져, 어머니가 자신과의 갈등을 어떻게 인지하는지가 남자 청소년의 심리적 안녕감에 영향을 주었을 가능성이 있다.

본 연구의 제한점과 후속연구를 위한 제언은 다음과 같다. 첫째, 본 연구에서는 온라인 설문업체의 패널로 가입되어있는 청소년 자녀를 둔 어머니들을 대상으로 어머니가 청소년 자 녀에게 함께 설문에 참여할 것을 권유하고 동의를 얻어 설문 이 진행되었기 때문에, 연구대상자들의 모-자녀 간 갈등수준 이 높지 않게 나타났을 가능성이 있다. 따라서 추후 연구에서 는 모-자녀 갈등의 정도를 구분하여 영향력의 차이를 재검토 해볼 필요가 있다. 둘째, 본 연구에서는 가족관계 중 가장 가까 운 관계인 모-자녀 간의 관계에서 상호 간의 관계적 측면이 개 인의 심리적 안녕감에 미치는 영향을 탐구하였다. 추후의 연 구에서는 아버지-자녀 간의 관계를 포함하여, 다양한 가족 간 의 역동이 가족구성원들의 심리적 안녕감에 어떠한 상호적 영 향을 미치는지에 대해 알아볼 필요가 있다.

이러한 제한점에도 불구하고 본 연구의 결과는 다음과 같 은 학문적, 실제적 의의가 있다. 첫째, 본 연구에서는 부모-자 녀관계에서 양방향적 영향력이 커지기 시작하는 청소년기의 자녀와 어머니의 심리적 안녕감에 영향을 미치는 가족관계적 측면의 요인을 자기-상대방효과를 통해 확인하였다는 데 의 의가 있다. 특히 본 연구의 결과는 가족체계적 접근을 통해 가 족 내의 한 하위체계인 모-자녀관계는 일방향적 관계가 아닌, 상호적 영향을 미치는 관계임을 실증적으로 설명하였으며, 가정 내에서 이루어지는 모-자녀 간의 의사소통과 상호적 관 계가 이들의 심리적 안녕감에 중요한 역할을 할 수 있음을 확 인하였다. 둘째, 어머니와 자녀가 인지한 모-자녀 의사소통이 모-자녀 갈등을 통해 심리적 안녕감에 미치는 경로에서 성차 를 확인하였다는 데 의미가 있다. 본 연구의 결과는 어머니와 청소년 자녀 간에 이루어지는 의사소통이나 갈등상황은 현상 그 자체뿐 아니라, 각 변인에 대한 어머니와 자녀의 인식에 따 라 서로에게 미치는 영향력이 다르게 나타난다는 것을 보여주 었으며, 자녀의 성에 따라서도 서로의 심리적 안녕감에 미치 
는 영향력이 다른 양상으로 나타날 수 있음을 보여주었다. 마 지막으로 본 연구의 결과들은 사회구성원들의 심리적 안녕감 향상에 기여할 수 있는 가족체계적 접근의 가족정책을 위한 기초자료로 활용될 수 있을 것이다. 또한 본 연구의 결과를 통 해 부모-자녀관계에서의 상호적 영향과 청소년기 성차에 대 한 다각적인 탐구가 활성화되기를 기대한다.

\section{Notes}

This article is a part of the first author's Doctor's thesis submitted in 2020, and was presented as a poster at the 2021 Annual Spring Conference of the Korean Association of Child Studies.

\section{Conflict of Interest}

No potential conflict of interest relevant to this article was reported.

\section{Ethics Statement}

All procedures of this research were reviewed by IRB (Ewha202006-0020-03).

\section{References}

\section{In English}

Allport, G. W. (1961). Pattern and growth in personality. New York: Holt, Rinehart and Winston.

Armentrout, J. A., \& Burger, G. K. (1972). Children's reports of parental child-rearing behavior at five grade levels. Developmental Psychology, 7(1), 44. doi:10.1037/h0032701

Becvar, D. S., \& Becvar, R. J. (2013). Family therapy: A systemic integration. Boston, MA: Pearson Education.

Bekhet, A. K., Zauszniewski, J. A., \& Nakhla, W. E. (2008). Loneliness: A concept analysis. Nursing Forum, 43(4), 207213. doi:10.1111/j.1744-6198.2008.00114.x

Bigner, J. J. (1989). Parent-child relations: An introduction to parenting. New York: Macmillan Publishers.

Blos, P. (1989). The inner world of the adolescent. In A. H. Esman
(Ed.), International annals of adolescent psychiatry (Vol. 1). Chicago, IL: University of Chicago Press.

Bowen, M. (1966). The use of family theory in clinical practice. Comprehensive Psychiatry, 7(5), 345-374. doi;10.1016/ S0010-440X(66)80065-2

Cook, W. L., \& Kenny, D. A. (2005). The actor-partner interdependence model: A model of bidirectional effects in developmental studies. International Journal of Behavioral Development, 29(2), 101-109. doi:10.1080/ 01650250444000405

Cooper, C. R., Grotevant, H. D., Moore, M. S., \& Condon, S. M. (1982, August). Family support and conflict: Both foster adolescent identity and role taking. Paper presented at the meeting of the American Psychological Association, Washington, D.C.

Crouter, A. C., \& Booth, A. (2003). Children's influence on family dynamics: The neglected side of family relationships. London: Routledge.

Deutsch, M. (1994). Constructive conflict resolution: Principles, training, and research. Journal of Social Issues, 50(1), 13-32.

Erikson, E. H. (1963). Childhood and society (2nd Ed.). New York: W.W. Norton \& Company.

Erikson, E. H. (1968). Identity: Youth and crisis. New York: W.W. Norton \& Company.

Hagerty, B. M., \& A. Williams. (1999). The effects of sense of belonging, social support, conflict, and loneliness on depression. Nursing Research, 48(4), 215-219. doi:10.1097/00006199199907000-00004

Hall, G. S. (1904). Adolescence: Its psychology and its relations to physiology, anthropology, sociology, sex, crime, religion and education (Vol. 2). Boston, MA: D. Appleton And Company.

Jung, C. G. (1969). Modern man in search of a soul (W. S. Dell \& C. F. Baynes, Trans.). New York: Harcourt, Brace, \& World. (Original work published 1985)

Kelley, H. H., Holmes, J. G., Kerr, N. L., Reis, H. T., Rusbult, C. E., \& van Lange, P. A. M. (2003). An atlas interpersonal situations. New York: Cambridge University Press.

Kelley, H. H., \& Thibaut, J. W. (1978). Interpersonal relations: A theory of independence. New York: Wiley.

Kenny, D. A. (1996). Models of non-independence in dyadic research. Journal of Social and Personal Relationships, 13(2), 279-294. doi:10.1177/0265407596132007

Kenny, D. A., Kashy, D. A., \& Bolger, N. (1998). Data analysis on social psychology. In S. T. Fiske, D. T. Gilbert, \& G. Lindzey (Eds.). Handbook of social psychology (4th ed., Vol. 1, pp. 233-265). New York: McGraw-hill.

Kupersmidt, J., Burchinal, M., Leff, S., \& Patterson, C. (1992, March). A longitudinal study of perceived support and conflict with parents from middle childhood through adolescence. Paper presented at the biennial meetings of the Society for Research on Adolescence, Washington, D.C.

Lahav-Kadmiel, Z., \& Brunstein-Klomek, A. (2018). Bullying 
victimization and depressive symptoms in adolescence: The moderating role of parent-child conflicts among boys and girls. Journal of Adolescence, 68, 152-158. doi:10.1016/ j.adolescence.2018.07.014

Ledermann, T., Macho, S., \& Kenny, D. A. (2011). Assessing mediation in dyadic data using the actor-partner interdependence model. Structural Equation Modeling: A Multidisciplinary Journal, 18(4), 595-612. doi:10.1080/107 05511.2011 .607099

Maslow, A. H. (1968). Toward a psychology of being (2nd ed.). New York: D. Van Nostrand Company.

Muraru, I.-D., \& Turlluc, M. N. (2015). Similarity, communication, and satisfaction in intimate relationships: The role of ideal standards. Psibologia Socială, 35(1), 109-122.

Ponnet, K., Wouters, E., Mortelmans, D., Pasteels, I., De Backer, C., van Leeuwen, K., \& van Hiel, A. (2013). The influence of mothers'and fathers' parenting stress and depressive symptoms on own and partner's parent-child communication. Family Process, 52(2), 312-324. doi:10.1111/famp.12001

Rogers, C. R. (1961). On becoming a person. Boston, MA: Houghton Muffin.

Ryff, C. D. (1989). Happiness is everything, or is it? Explorations on the meaning of psychological well-being. Journal of Personality and Social Psychology, 57(6), 1069-1081. doi:10.1037/0022-3514.57.6.1069

Sonja, Č. K. (2016). Parent-adolescent conflict style and conflict outcome: Age and gender differences. Psihologija, 49(3), 245-262. doi:10.2298/PSI1603245C

Warner, E. L., \& Steel, B. S. (1999). Child rearing as a mechanism for social change: The relationship of child gender to parents' commitment to gender equity. Gender \& Society, 13(4), 503-517. doi:10.1177/089124399013004005

White, J. M., \& Klein, D. M. (2008). Family theories (3rd ed.). Thousand Oaks, CA: Sage Publications.

\section{In Korean}

Ahn, N.-Y., \& You, Y.-D. (2013). The relationships between perceived parents-adolescents communication and adolescents' depression/happiness-Focused on the mediation effect of negative automatic thoughts-. Korea Journal of Counseling, 14(5), 3201-3215. doi:10.15703/kjc.14.5.201310.3201

Bae, S. A. (1999). A study on the cognitive factors affecting adolescence's psychological well-being (Master's thesis). Retrieved from http://www.riss.kr/link?id=T11012993

Baek, M. S. (2000). A study on the parents-adolescent conflicts (Master's thesis). Retreived from http://www.riss.kr/link?id= T7607268

Chae, K. S., \& Hwang, H. J. (2014). The relationship among parent-child communication types and children's perceived happiness. Journal of Korean Hyo Studies (20), 159-190.

Choi, H. J. (2016). The influence of conflicts with parents perceived by adolescents on psychosocial wellbeing (Master's thesis).

Retrieved from http://www.riss.kr/link?id=T14037484

Chun, J. W., \& Park, M. S. (2006). A test of causal model for motivation for job performance, job satisfaction and psychological well-being of the elderly. Journal of the Korea Gerontological Society, 26(3), 521-545.

Chun, Y.-H., \& Ko, J.-H. (2005). The effects of self-esteem, personality, and communication patterns on motheradolescent conflict: An application of APIM. The Korea Journal of Youth Counseling, 13(2), 47-60.

Han, T. Y., \& Lee, S.-L. (2005). The relationships between adolescents' emotion-related factors and stress at school: The effects of experienced emotion, expressed emotion, and emotional intelligence. The Korean Journal of School Psychology, 2(1), 37-58.

Hwang, Y. E., \& Doh, H. S. (2004). Maternal parenting, motheradolescent conflict, and individuation of adolescents. Korean Journal of Child Studies, 25(2), 133-154.

Jang, H. S. (2005). Adolescent-mother conflicts and their related variables. The Korean Journal of Developmental Psychology, 18(1), 97-113.

Jang, Y.-E., \& Lee, Y.-J. (2015). A study of adolescent's happiness and adolescent's perception of parent-child communication, peer relationships, study stress. Korea Institute of Youth Facility \& Environment, 13(4), 147-156.

Jo, G.-S., \& Cho, J.-R. (2004). Psychological well-being of employed and nonemployed married women: Genderrole attitude, life event stress, and marital satisfaction as a moderator. The Korean Journal of Woman Psychology, 9(3), $27-41$.

Jung, J. (2014). An analysis on the casual model between parentchild' negative interaction and adolescent' aggression: Focusing on sex differences. Studies on Korean Youth, 25(2), 237-263. doi:10.14816/sky.2014.25.2.237

Jwa, H. (2018). The gender and age differences in the effect of parenting style on adolescent internalizing problem and externalizing problem. Korean Journal of Youth Studies, 25(2), 219-245. doi:10.21509/KJYS.2018.02.25.2.219

Keum, M. J., Kim, T. H., \& Kim, E. Y. (2002). Basics of Youth Counseling. Seoul: Korea Youth Counseling Institute.

Kim, B. J., Park, Y. S., \& Chun, Y. M. (2005). The effects of economic difficulties, economic copying behavior, and communication within family on mental health of housewives. The Korean Journal of Woman Psychology, 10(1), 37-59.

Kim, K. (2006). Relationship of psychological well-being with family relationship, friendship, and school adjustment of high school and college students (Master's thesis). Retreived from http:// 
www.riss.kr/link?id=T10268190

Kim, O. N. (2004). Single mother family's mother-adolescent conflicts, copings and psychological well-being. Korean Journal of Human Ecology, 13(4), 507-519.

Kim, O. N., \& Kim, K. S. (1994). Communications and family stress between mother and adolescent (Master's thesis). Retrieved from http://www.riss.kr/link?id=T1667844

Kim, T., \& Ki, P. (2019). Effect of family relationships on depression in middle-aged parents with teenage children: Focusing on the mediating effect of loneliness. Family and Culture, 31(3), 1-33. doi:10.21478/family.31.3.201909.001

Kim, Y., \& Ahn, S. (2008). Family cohesion, family adaptability, parent-adolescent communication, family conflict, and adolescents' depression \& delinquency. Korean Journal of Youth Studies, 15(2), 1-30.

Kong, I., Yi, E., \& Lee, J. (2005). Adolescents' conflict, communication with parents and their self-concept. Korean Journal of Human Ecology, 14(6), 925-936.

Lee, H.-G. (2016). The effects of depression and psychological wellbeing on leisure activities in midlife. Northeast Asia Tourism Research, 12(2), 129-148.

Lee, M.-K., \& Lee, Y.-J. (2015). A qualitative study on parental development experiences of women in their fifties. Family and Culture, 27(2), 61-97.

Lee, S., Kim, H.-J., \& Lee, Y. (2006). Resource exchanges between mothers and adolescent children. Korea Journal of Population Studies, 29(1), 97-131.

Lee, S., Lee, Y., \& Kim, H.-J. (2008). The gendered pattern of parental support and control over adolescent children: A comparative analysis. Korea Journal of Population Studies, 31(2), 45-76.

Lee, Y.-M., Min, H.-Y., \& Lee, Y.-J. (2005). The impact of parents marital conflict and parent-adolescent communication on college students psycho-social adjustment. Journal of Families and Better Life, 23(5), 53-62.

Lim, J., \& Chun, J. S. (2012). Effect of parenting behaviors and parent-child communication on school adjustment among male and female adolescents. Korean Journal of Youth Studies, 19(8), 169-190.

Lim, Y.-J., Ko, Y.-G., Shin, H.-C., \& Cho, Y. (2012). Psychometric evaluation of the Mental Health Continuum-Short Form (MHC-SF) in South Koreans. Korean Journal of Psychology: General, 31(2), 369-386.

Min, H. Y. (1991). The relation between juvenile deliquency and parent-Adolescent communication, family cohesion and adaptability (Unpublished master's thesis). Seoul National University, Seoul, Korea.

Moon, K.-J., \& Oh, K. J. (2002). The relationship between perceived parental behaviors and early adolescents' depression and anxiety. The Korean Journal of Clinical
Psychology, 21(1), 29-43.

Moon, K.-J. (2004). The effect of discrepancy between adolescent autonomy need and parental allowance on depression and rulebreaking behavior: mediating effect of conflict with parents (Doctoral dissertation). Retrieved from http://www.riss.kr/ link?id=T9500673

Moon, S. K. (2005). An analysis of prediction variables affecting adolescents' parent-child relationship. Korean Journal of Family Welfare, 10(3), 105-125.

Nam, H. K. (2012). Godeunghagsaeng-i jigaghan bumogidaega seongyeoghal jeongchegam-eul maegaelo jinlopobu-e michineun yeonghyang: seongchamohyeong-ui geomjeung [고등학생이 지 각한 부모기대가 성역할 정체감을 매개로 진로포부에 미치 는 영향: 성차모형의 검증](Master's thesis). Retreived from http://www.riss.kr/link?id=T12868103

Park, E. J., \& Kim, K. S. (1995). Communications and family cohesion $\&$ adaptability between mother and adolescent. Family and Environment Research, 33(5), 27-38.

Park, H.-K., \& Choi, T. (2012). The effect of the love of married couple and attachment and autonomy of mother upon mid-life depression of middle-aged female. Korean Journal of Educational Therapist, 4(2), 39-54.

Park, M.-S., Cha, Y.-Y., \& Kim, H.-K. (2014). A study on communication and conflicts between children and their parents of multi-cultural families living in rural areas. Multicultural Education Studies, 7(4), 101-122. doi:10.14328/MES.2014.12.31.101

Park, S.-Y., \& Lee, H. (2013). Determinants of subjective wellbeing among Korean adolescents. The Korean Journal of Stress Research, 21(2), 73-84.

Park, Y. S., \& Kim, U. C. (2000). The impact of the changing parent-child relationship on adolescents' functioning: Comparison of primary, junior high, senior high and university students. Korean Journal of Educational Research, 38(2), 109-146.

Seo, S. G., Jeon, J. H., An, J. S., \& Choeng, Y. S. (2015). An exploratory study on the conflicts in the relationship between middle-aged parents and university student children. The Korean Journal of Clinical Psychology, 34(4), 971-990. doi:10.15842/kjcp.2015.34.4.006

Shin, H.-K. (2002). The relationship of academic stress, negative affectivity, alexithymia, and perceived parenting behavior to somatization in adolescents. The Korean Journal of Clinical Psychology, 21(1), 171-187.

Shin, S. H., Ko, S. J., Yang, Y. J., Oh, H. S., Jang, M. Y., \& Choi, J. M. (2014). Comparison of boys' and girls' families for actor and partner effect of stress, depression and parentadolescent communication on middle school students' suicidal ideation: Triadic data analysis. Journal of Korean Academy of Nursing, 44(3), 317-327. doi:10.4040/jkan.2014.44.3.317 
Song, M. (1995). Developmental psychology. Seoul: Hakjisa.

Yeon, E.-M., Yoon, H.-O., \& Choi, H.-S. (2016). Moderating effects of family incomes on the relationship among marital conflict, depression, and parenting attitude: The actorpartner interdependence model. The Journal of Korea Open Association for Early Childhood Education, 21(2), 1-28.

Yoon, J.-E., \& Choi, M.-K. (2004). Maternal parenting, motheradolescent conflict, and adolescent self-esteem. Journal of Families and Better Life, 22(5), 237-251.

Yu, J. P. (2012). The basics and interpretation of structural equation modeling. Seoul: Hannarae.

\section{ORCID}

Yeon Soo Cho http://orcid.org/0000-0002-8086-644X

Sae-Young Han http://orcid.org/0000-0001-8207-5927
Received June 24, 2021

Revision received July 18, 2021

Accepted August 25, 2021 